\title{
The Politics of Public Engagement \\ Reclaiming community?
}

\section{Sharon Clancy}

Doctoral Researcher, University of

Nottingham

Gateways: International Journal of Community Research and Engagement Vol 8/No 1 (2015): 160-66 (C) UTSePress and the author

ISSN 1836-3393
Back in 2008, as a rather green new Head of Community Engagement at a Russell Group university, I attended a session at the University of Brighton on 'radical community/university engagement'. It was a moment of epiphany for me and shaped much of my efforts and thinking for the six years I was in this post at the university.

The former Vice-Chancellor at Brighton, Sir David Watson (who sadly died in February of this year), was my touchstone, as he has been for many other people, exploring the history and purpose of Higher Education and civic/community engagement. He spoke passionately about civic engagement as a means of engaging with society through knowledge exchange and dialogue, not knowledge transfer, but 'dialogue across the boundary between the University and its community which is open-ended, fluid and experimental' (Watson 2003, p. 16). He referenced the 2002 Association of Commonwealth Universities' (ACU) document, which described engagement as a 'thoughtful, argumentative interaction with the non-university world' (cited in Watson 2007, p. 3), explicitly connecting teaching and learning with the 'wider world' and bringing practitioners and researchers together as both citizens and neighbours.

Professor Stuart Laing, then Pro Vice-Chancellor (Academic Affairs) for the University of Brighton, argued at the same conference for a reimagining of the university's social role, moving beyond enriching the student experience, or philanthropy, or imparting 'civilised values'. He argued that university/public engagement should not be solely a mechanism for reputation management or positive marketing within a university but, instead, should be a vital space in which we might seek to forge equality of esteem and of priority for both social and economic engagement.

It will touch on massive and omnipresent areas of our actual social life - areas which are at the heart of the fabric and the material base of our society - matters which affect all of us every day of our lives.

(cited in Clancy 2011) 
Professor Laing gave examples of contemporary issues at the heart of modern society, social urgencies such as the role of care in the community and the status of carers, public health debates on the future of the NHS, the shifting role of the voluntary and community sector in civil society, medical ethics and the public understanding of science (including social science).

As someone from a community sector and social policy background, in terms of my career, and as a woman from a working-class mining town, this resonated with me. I could see the value in university-based learning reaching out to communities and responding to their real research needs, and that my role might play a small part in this. Finding myself in a resource-rich institution after years of scrabbling to survive in the voluntary sector, where research tended to fall off the agenda due to the urgencies of survival, I saw an opportunity to bring my own experience of two worlds together.

I had studied in, and taught in, a range of different universities, and had grown in my conviction that there should be space for practitioners to come together with academics to forge real social change. Much of my own teaching had been born out of my practitioner experience. Thus, I had spent a period teaching social policy, practitioner-based research and community capacity building prior to my appointment at the University, whilst working as CEO of a Council for Voluntary Services in an area of the North East Midlands hard hit by closures in the mining, engineering and textile industries. This was a place where wave after wave of policy applications seemed to make no impact in the face of the messiness, complexity and frank inequality of real community life in the area our organisation served.

I had been attracted by the concept of praxis - the coupling of theory and action expressed in informed, committed action - and, by extension, the role of pracademic, suggestive, as it is, of bringing academic knowledge and skill together with actionbased practice. I knew that people were looking for answers, or at least help with debating the exigencies of their lives and seeking solutions. I had questioned many times why we were not better connected with academic activity which was looking to respond to real social issues and the lived experiences of the communities in which I had lived and worked. The world of the University, instead, seemed rather remote.

What I greeted so enthusiastically in my new University-based role was the prospect of acting as a broker between these two worlds.

Brokers serve as the glue that breathes life into the networks that constitute relationships and sustain them over time. The most effective brokers are those who have occupied significant positions as both academics and practitioners - or so-called pracademics. These adaptable and cross-pressured actors serve the indispensable roles of translating, coordinating and aligning perspectives across multiple constituencies. (Posner 2009, p. 6) 
Around the time I started my public engagement role at the University, in 2008, the Higher Education Funding Council for England (HEFCE) founded an initiative for establishing a coordinated approach to recognising, rewarding and building capacity for public engagement, called the Beacons project. Its express objective was:

To create a culture within UK Higher Education where PE [public engagement] is formalised and embedded as a valued and recognised activity for staff at all levels, and for students. (NCCPE website)

Out of this funding came the National Co-ordinating Centre for Public Engagement (NCCPE), which aims to coordinate, capture and share learning about public engagement between and across UK Higher Education institutions, communities and research institutes. The NCCPE has been a constant source of inspiration (and, dare I say, hope) to me and to many others working in this space. To use its own words about its work, and that of the Beacons, they have worked on 'critiquing, challenging and nudging their institutional systems and cultures to make them more supportive of engagement' (NCCPE website).

To that end, the NCCPE team have been clear from the start that public engagement should be broadly defined and understood. It is not about 'specialists talking to non-specialists'. Instead, their definition focuses on 'mutual benefit' and on increasing the HE sector's 'relevance to, and impact on, civil society' (NCCPE website). They actively acknowledge that more emphasis needs to be placed on recognising that people are experts in their own lives, and should be respected as such. The role of brokers to catalyse and stimulate this work was explicitly understood in both the Beacons' projects and those of its successor, the Catalyst program (funded by Research Councils UK). Before any change of ethos and approach can take place in Higher Education institutions - often monolithic and adamantine cultures - practitioners who understand the world of both 'community' and 'university' have a vital role in critically investigating the rhetoric and definitions around engagement, and the building of resources and structures to embed change.

There is no doubt that much excellent work has happened as a result of the vigorous focus on public engagement since 2008, with bodies like the NCCPE and HEFCE at the vanguard. There is innovative and exciting university-based practice, across both preand post-1992 institutions, focusing on regeneration and renewal, community studies on Council estate culture, policy debate, and discussion at a civic level on health and social care issues, artsbased activities, which use local expertise to inform local history exhibitions, museum activity and research programs, and online discussion spaces on participation and democracy. These are just some instances of the outpouring of creativity in response to the challenge of making public engagement count. 
The Research Excellence Framework (REF) requirement to demonstrate public impact has also helped stimulate thinking about how we engage with 'publics' as part of research activity and how we demonstrate this. The REF 2014 showed an uplift in quality across all research and a sharpened focus on impact as 'any effect on, change or benefit to the economy, society, culture, public policy or services, health, the environment or quality of life, beyond academia' (REF website).

I am minded of David Watson's (2007) commentary on first, second and third order university engagement - the university as 'ethical beacon' - as evidenced by the kinds of research they do and the student body they attract (who they are - first order); the contracts, partnerships and stakeholder engagement they foster 'the engaged university' (what they do and with whom - second order); and their expression of membership - how this looks in terms of academic partnerships, levels of honesty and integrity, the rights and responsibilities they recognise and their capacity for organisational reflexivity (third order). The work of NCCPE and HEFCE has certainly stimulated rightful debate about the role of the university in contemporary life.

Public engagement has a global face too, which is testimony to its growth in importance since the early 2000s. The Talloires Network, formed in 2005, brings together heads of universities from 23 countries from across the globe. Their mission is described thus:

We believe that higher education institutions do not exist in isolation from society, nor from the communities in which they are located. The Talloires Network envisions universities around the world as a vibrant and dynamic force in their societies, incorporating civic engagement and community service into their research and teaching mission. (Talloires Network website)

The Network profiles exceptional academics and has created the MacJannet Prize for Global Citizenship. It also provides resources, newsletters and materials, and a list of civic engagement experts, as well as staging regional and global conferences. It was actively supported by David Watson, and its members contribute to the NCCPE's annual public engagement conference, Engage.

However, despite this creative upsurge in response to public engagement, NCCPE's key point from the start has been that, in order for public engagement to be 'real', it needs to be part of university culture, the fabric of the organisation's systems, structures and ethos. It should not be a 'bolt on', inadequately resourced and knocked into the long grass by the twin pressures of financial exigency and social conservatism. The NCCPE suggests that real barriers in the form of embedded and engrained values and ways of working continue to exist and that, after several years of activity and innovation, it is still at an early stage of the journey (NCCPE n.d.). Essentially, I would argue that the role of practitioners/pracademics in fostering debate about the realities of engagement is in itself profoundly political and that it represents 
a space of contestation between the demands of an increasingly marketised and neo-liberal approach to education and a push towards greater social responsibility. It can be a lonely and sometimes profoundly challenging place to be.

Russell Group universities do not routinely draw students from their local area; in that sense, they are not 'of' the community. There is a robust focus on increasing social mobility and 'widening participation', with an emphasis on engagement with schools, but wider links with communities are often not central to the activity of such universities and community expertise is not routinely sought to ease these relationships.

The loss of adult education as a key space for understanding communities and fostering collaboration is felt keenly by those who recall its critical role in acting as a bridge to deep and genuine public engagement. Much of the groundbreaking work of the 60s, 70s and early 80s has disappeared, along with Adult Education departments. One senior academic I talked to recently spoke of bottom-up, community-based short-term courses as a 'nursery slope' into Higher Education in economically strapped communities. Without this, both practitioner expertise at community level and networks of engaged multi-disciplinary academics coming together with community groups and individuals to tackle specific issues of social, philosophical and economic urgency has been leeched away. Along with Adult Education structures has gone an important emphasis on dialogue, debate and talking to people in response to their current position, beyond the lecture hall, where research proposals are forged on the ground from real and defined need. In my academic colleague's view, the shift over the last two decades has been towards a 'default position' version of public engagement, with community engagement conflated either with a focus on widening student access and participation from 'disadvantaged communities' or, most prominently, with business engagement. This view is supported by findings in the Higher Education Business and Community Interaction Survey for 2013 (HEFCE 2014), which shows that the university in which I previously worked provides fewer social outreach events and is involved in fewer partnerships with community and civic actors than other universities, instead favouring engagement with private business as its preferred method of outreach.

It is hard for me as a broker/pracademic to avoid some degree of 'pessimistic analysis' or at least a strong dose of realism, despite the many positive developments identified above. The danger is always that the default position is safest, especially in times of austerity, when money talks. Business brings with it the possibility of research funding in areas such as science, technology and engineering - and this is proper. But it is disingenuous, at best, to present this kind of engagement as 'public', as it sometimes is. My own early experience of business and community engagement seminars was of a much greater emphasis on (and understanding of) business and little appreciation of how to do community 
engagement well. Much of the expertise garnered in the field of adult education through extra-mural activities, communityparticipatory research and community-based education, as commented on above, is now gone or is sitting outside the university sector in small community-based organisations.

However, I am heartened and encouraged by a resurgence of interest in the power of Adult Education, these same smaller organisations continuing to keep alive an alternative vision of radical, informal education which is about individual and cultural transformation. The Raymond Williams Foundation, particularly, with which I am personally involved, is a vital voluntary organisation that utilises traditions of informal, often residential, community-based discourse on democracy and social justice, in line with Williams' lifelong social project, the creation of 'an educated and participating democracy' (Williams 1961, 2001, p. 389). It does this through its support fund which was created to help adults - especially the financially and educationally disadvantaged - to attend annual residential lecture-based courses, and by helping to stimulate discussion on big social, political, philosophical and cultural themes through its support of public forums. This includes emerging informal networks such as Philosophy in Pubs (PiPs) - a community organisation which supports grassroots, community-based philosophy in public venues for people with a shared passion for inquiry - Sci-bars, and pub/ cafe lectures and discussion circles generally.

The Foundation's starting point for these networks is that community-university engagement, unlike its more broadly conceived cousin, 'public', is engagement which is by necessity complex and requires the long view, as Williams asserted. It brings with it little obvious financial incentive. Its cultural spaces in the voluntary sector and in Adult Education have been laid waste by funding cuts and the march of 'Plan X', Williams' description of the impact of neo-liberalism, which can seem like the only discourse in town. It requires a process of building trust and mutuality over many years. So, whilst universities may present an 'open door' to 'publics' with which they are comfortable, I am minded of Chomsky's (1999) famous quote 'freedom without opportunity is a devil's gift, and the refusal to provide such opportunities is criminal'. Freedom means nothing without the opportunity and power to exercise it, and communities which are deemed 'hard to reach' are only so perhaps because there is not sufficient will to engage with them and because university systems and structures prevail against them. For me, as a pracademic, the Raymond Williams Foundation version of informal adult education provides the space to critically investigate the rhetoric around engagement. We need this detailed scrutiny if we are to progress with community engagement, create freedom and opportunity, and forge social change in line with Laing's and Watson's vision. 


\section{REFERENCES}

Chomsky, N 1999, Profit over people - neoliberalism and global order, Seven Stories Press, New York, pp. 91-92.

Clancy, S 2011, 'Social justice and higher education: Universities as agents of change in the context of the "Big Society"', MA Dissertation, University of Nottingham.

HEFCE 2006, 'HEFCE strategic plan 2006-11', Higher Education Funding Council, London, viewed 21 July 2015, www.hefce.ac.uk/pubs/ HEFCE/2006.

HEFCE 2014, 'Higher education business and community interaction survey', viewed 30 June 2015, www.hefce.ac.uk/media/hefce/content/ pubs/2014/201410/HEFCE2014 10.pdf.

NCCPE, viewed 5 January 2015, www.publicengagement.ac.uk.

NCCPE n.d., 'The history of the National Co-ordinating Centre for Public Engagement', viewed 21 July 2015, www.publicengagement.ac.uk/sites/ default/files/publication/history of the nccpe.pdf.

Posner, P 2009, The pracademic: An agenda for re-engaging practitioners and academics', Public Budgeting \& Finance, vol. 29, no. 1, pp. 12-26.

REF, viewed 20 May 2015, http://results.ref.ac.uk/Results/SelectUoa.

The Talloires Network, viewed 21 May 2015, http://talloiresnetwork.tufts. edu/who-we-ar/.

Watson, D 2003, 'Universities and civic engagement: A critique and a prospectus', keynote address presented at the 2 nd biennial Inside-out conference, The Civic Role of Universities - Charting Uncertainty: Capital, Community and Citizenship, Brighton, UK.

Watson, D 2007, Managing civic and community engagement, Open University Press, Maidenhead, UK.

Williams, R 1961, The long revolution, Chatto \& Windus, London; 2001, Broadview Press, Canada. 